\title{
Fatores de risco na transmissão do lentivírus caprino pelo sêmen
}

\author{
Alice Andrioli(1), Aurora Maria Guimarães Gouveia ${ }^{(2)}$, Almir de Sousa Martins ${ }^{(3)}$, \\ Raymundo Rizaldo Pinheiro(1) e Diones Oliveira Santos ${ }^{(1)}$
}

\begin{abstract}
(1)Embrapa Caprinos, CE 178, Estrada Sobral/Groaíras, Km 4, Zona Rural, CEP 62011-970 Sobral, CE. E-mail: alice@cnpc.embrapa.br (2)Universidade Federal de Minas Gerais (UFMG), Escola de Veterinária, Dep. de Medicina Veterinária Preventiva, Av. Antônio Carlos, no 6.627, Pampulha, CEP 31270-901 Belo Horizonte, MG. E-mail: aurora@vet.ufmg.br (2)UFMG, Instituto de Ciências Biológicas, Dep. de Fisiologia e Biofísica. E-mail: alisbete@icb.ufmg.br
\end{abstract}

Resumo - O objetivo deste trabalho foi avaliar a presença do DNA pró-viral do lentivírus caprino (LVC) em ejaculados de machos infectados naturalmente, e verificar a influência da lavagem do sêmen e da presença de inflamação testicular sobre a carga viral. Foram realizadas oito coletas de sêmen de sete reprodutores soropositivos para o LVC: quatro antes dos animais sofrerem dano testicular e quatro depois. Entre as coletas realizadas na mesma semana, em uma, o ejaculado era lavado, para retirada do plasma seminal, e na outra, não. O DNA pró-viral do LVC foi identificado pela reação em cadeia da polimerase Nested (PCR Nested), e pelo isolamento viral. O vírus foi isolado em 7,1\% das amostras. A PCR identificou o DNA pró-viral em 35,7\% do total das amostras: 17,9\% nas amostras lavadas e 53,6\% das amostras de sêmen integrais. O dano ao testículo permite maior fluxo do vírus para o sêmen, pois antes do dano, 21,4\% das amostras foram positivas e pós-dano, 50\%. A transmissão do LVC pelo sêmen de reprodutores caprinos é potencializada pela presença de inflamações testiculares e pelo fato de o sêmen criopreservado conter o LVC na forma infectante.

Termos para indexação: reprodução, PCR, artrite-encefalite caprina, transmissão.

\section{Risk factors in caprine lentivirus transmission through semen}

\begin{abstract}
The objective of this work was to evaluate the presence of the DNA provirus of the caprine lentivirus (LVC) in ejaculates of naturally infected males, and to verify the influence of the wash of the semen as well as the presence of testicle inflammation on the viral load. Eight semen collections of seven soropositive reproducers were accomplished, four before testicle injury and four after injury. Amongst the collections carried out at the same week, in one the ejaculate was washed, to withdraw the plasma seminal, and in the other it was not. The provirus DNA was identified both by Nested polymerase chain reaction technique (Nested PCR) and by the viral isolation. The virus was isolated in $7.1 \%$ of the samples. The PCR identified the provirus DNA in $35.7 \%$ of all samples, $17.9 \%$ in the washed samples and $53.6 \%$ of the integral semen samples. The injury of the testicle tends to greater flow of virus for the semen, therefore, before injury, $21.4 \%$ of the samples were positive and after-injury, $50 \%$. Risk of transmission of the LVC by semen of goat reproducers is strengthened by the presence of testicle inflammations and the fact that the criopreserved semen contains the LVC in infecting form.
\end{abstract}

Index terms: reproduction, PCR, caprine arthritis encephalitis, transmission.

\section{Introdução}

O lentivírus caprino (LVC) é o agente etiológico da artrite-encefalite caprina (AEC), uma enfermidade crônica, incurável, de alta prevalência em rebanhos leiteiros nacionais e associada à perdas econômicas. Há grande necessidade de pesquisa dos modos de transmissão desse vírus para o delineamento eficiente de medidas de controle e possível erradicação.

O avanço das técnicas de conservação de germoplasma, aliado ao aumento da importância econômica da caprinocultura, favorece o intercâmbio de sêmen. No entanto, pouco tem sido estudado sobre a possibilidade de transmissão de microrganismos via sêmen e embrião, bem como, quais as medidas ou testes de diagnóstico que podem assegurar que estes materiais estejam livres de patógenos, diminuindo o risco da entrada de novas enfermidades nos rebanhos.

O sêmen pode ser contaminado por microrganismos que afetam diretamente os órgãos reprodutores ou pelo sangue e líquidos tissulares que carreiam microrganismos para estes órgãos (Hare, 1985; Thibier \& Guérin, 2000). 
Em pequenos ruminantes, vários patógenos foram detectados no sêmen, com transmissão potencial ou comprovada (Hare, 1985; Thibier \& Guérin, 2000), incluindo os lentivírus que infectam caprinos (LVC) e ovinos (Maedi Visna - MVV) (Concha-Bermejillo et al., 1996; Andrioli et al., 1999; Travassos et al., 1999; Preziuso et al., 2003). Outros lentivírus responsáveis por infeções em bovinos, felinos, primatas e humanos, foram, igualmente, detectados no sêmen (Mermin et al., 1991; Jordan et al., 1995; Nash et al., 1995).

A principal via de transmissão do LVC é a digestiva, seguida pelo contato prolongado com animais infectados (Adams et al., 1983; Rowe et al., 1992), porém, nem toda infecção pelo LVC pode ser atribuída a estas duas vias de transmissão, visto que o vírus tem se mantido, por anos, em rebanhos submetidos a rígidos programas de controle da AEC. A comprovação da presença do lentivírus no sêmen reforça a possibilidade da transmissão do LVC pela via sexual. Rowe et al. (1992) observaram maiores taxas de soro-conversão em fêmeas cobertas por machos soropositivos do que naquelas cobertas por machos negativos.

Em humanos, a transmissão dos lentivírus pelo sêmen depende do estágio da doença, do estado imunológico ou nutricional do paciente e da associação com outras enfermidades (Alexander, 1990). Em caprinos, pouco se conhece sobre fatores que interferem na presença dos LVC no sêmen, porém como os lentivírus infectam monócitos e macrófagos (Nash et al., 1995; Quayle et al., 1997), a presença de inflamações ou infecções no órgão reprodutor poderia desencadear o maior fluxo destas células inflamatórias, resultando em aumento da carga viral no sêmen. Concha-Bermejillo et al. (1996) e Preziuso et al. (2003) detectaram o lentivírus ovino no sêmen de carneiros, concomitantemente, infectados por Brucella ovis. A presença de leucócitos foi constatada nos ejaculados de todos os animais.

Há ainda a possibilidade dos vírus estarem presentes no sêmen na forma livre e como os vírus geralmente não infectam os espermatozóides (Nash et al., 1995; Travassos et al., 1999), cogita-se o uso de métodos físicos para separar os espermatozóides do fluido seminal, visando a eliminação dos patógenos. No entanto, Bielanski et al. (1992) relataram que os resultados não foram confiáveis para a remoção do vírus da diarréia bovina viral (BVD) no sêmen.

A fim de determinar a presença do LVC no sêmen de reprodutores caprinos naturalmente infectados, foi utilizada a técnica de reação em cadeia da polimerase
Nested (PCR-Nested), por possuir alta sensibilidade e especificidade para diagnóstico de vários agentes etiológicos, até mesmo o LVC, em diversos tipos de amostras clínicas (Barlough et al., 1994), aliada à técnica clássica de isolamento viral.

O objetivo deste trabalho foi detectar a presença do DNA pró-viral do LVC em ejaculados de machos naturalmente infectados e com sinais clínicos da AEC, avaliando a influência da lavagem do sêmen e da inflamação testicular, induzida por lesão traumática local, sobre a carga viral.

\section{Material e Métodos}

Foram utilizados sete reprodutores caprinos, criados em sistema intensivo, com dois anos de idade, sendo dois da raça Pardo Alpina, dois Anglo Nubiana, um Saanen e dois mestiços (Pardo Alpino/Moxotó) infectados naturalmente com o LVC, com manifestações clínicas da enfermidade e comprovação sorológica por imunodifusão em gel de ágar (IDGA).

As coletas de sêmen foram realizadas por eletroejaculação, visto que os animais apresentavam estado avançado de artrite, que os impossibilitava de realizar a monta. Foram realizadas oito coletas de sêmen de cada reprodutor, duas vezes por semana, com dois dias de intervalo.

Das oito coletas de sêmen realizadas, quatro ocorreram antes, e quatro depois de os machos sofrerem dano testicular visando ao maior fluxo de leucócitos para os testículos, que são as células de eleição do LVC. O dano foi provocado pela perfuração de um dos testículos com trocáter de $4 \mathrm{~mm}$ de diâmetro, sob anestesia regional. Foi coletado sangue dos machos, antes e até dez dias depois do dano testicular, para avaliação do quadro leucocitário.

Entre as coletas realizadas na mesma semana, em uma o ejaculado era lavado, para retirada do plasma seminal, e na outra não, com a finalidade de avaliar se a retirada do plasma seminal reduziria a carga viral no sêmen.

$\mathrm{Na}$ lavagem do sêmen, utilizou-se solução Krebs-Ringer-Fosfato, na proporção de nove partes da solução para uma parte de sêmen, com centrifugação a $2.000 \mathrm{~g}$ durante 10 minutos. Foi adicionado diluente à base de leite desnatado, glicose e glicerol, ao sêmen lavado.

As amostras foram envasadas, submetidas aos vapores de nitrogênio líquido e em seguida imersas no nitrogênio, para proceder-se o congelamento. Depois 
dessa etapa, as paletas foram transferidas para o botijão criobiológico e posteriormente armazenadas a $-80^{\circ} \mathrm{C}$.

As amostras de sêmen e controles positivo e negativo foram inoculadas em monocamadas de células de membrana sinovial caprina (MSC) obtidas a partir de explante de cabrito negativo para o LVC. As amostras (200 $\mu \mathrm{L}$ de cada) e os controles foram previamente tratados com $4 \mu \mathrm{L}$ de garamicina $\left(80 \mu \mathrm{g} \mathrm{mL}^{-1}\right), 2 \mu \mathrm{L}$ de penicilina/estreptomicina (200 $\left.\mathrm{UI} \mathrm{mL}^{-1}\right)$ e $1 \mu \mathrm{L}$ de

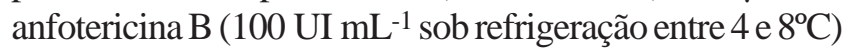
por 12 horas. Nos controles positivo e negativo, foram utilizados, respectivamente, sobrenadante de células de MSC inoculadas ou não com o LVC (amostra padrão CAEV-Cork).

As amostras e os controles foram diluídos 1:5 em meio essencial mínimo (MEM), sendo então inoculados $100 \mu \mathrm{L}$ de cada amostra, em duplicata, em placas de 24 poços sobre monocamada semiconfluente de MSC e mantidos em meio MEM, com 5\% de soro fetal bovino, $1 \%$ de anfotericina e $2 \%$ de penicilina e estreptomicina. Os cultivos foram mantidos por 63 dias em estufa com $5 \%$ de $\mathrm{CO}_{2}$, com trocas de meio a cada sete dias e passagem de células a cada 21 dias, sendo a monocamada examinada diariamente em microscópio invertido para verificação de efeito citopático característico, isto é, presença de células multinucleadas ou sincícios. Depois da última passagem de células, foi realizada a coloração da monocamada com solução de cristal violeta a $0,1 \%$ para melhor visualização do efeito citopático.

Foram preparados controles positivo e negativo para a PCR a partir de monocamadas de células de MSC inoculadas ou não com amostra do LVC de referência, respectivamente. As suspensões celulares foram obtidas por tripsinização das monocamadas. Depois de centrifugadas (6.500 $\mathrm{g}$ por 5 minutos) e submetidas a duas lavagens com $10 \mathrm{~mL}$ de solução tampão fosfato (PBS), as células foram ressuspendidas em tampão hipertônico (0,32 M sacarose; $10 \mathrm{mM}$ Trizma hydrochloride, $\mathrm{pH} \quad 7,5 ; 5,0 \mathrm{mM} \quad \mathrm{MgCl}_{2}$; 1,0\% Triton X 100), para lise do citoplasma (Higuchi, 1989) durante cinco minutos, em temperatura ambiente. Em seguida, o material foi centrifugado (2.500 rpm por 10 minutos), sendo o sedimento lavado com PBS e ressuspendido em $250 \mu \mathrm{L}$ de tampão de PCR $(10 \mathrm{mM}$ Tris-HCl, pH 8,0; $50 \mathrm{mM} \mathrm{KCl;} 1,0 \mathrm{mM} \mathrm{MgCl} 2 ; 5 \%$ glicerol; 0,05\% Tween20) e tratado com $100 \mu$ g de proteinase $\mathrm{K} \mathrm{mL}^{-1}$, durante 60 minutos, a $56^{\circ} \mathrm{C}$. Finalmente, a proteinase $\mathrm{K}$ foi inativada a $100^{\circ} \mathrm{C}$ por
10 minutos e as amostras acondicionadas e armazenadas sob refrigeração e, posteriormente, a $-20^{\circ} \mathrm{C}$.

Para extração do DNA genômico viral, as amostras de sêmen foram filtradas, individualmente, em coluna de Sephacryl S-400, como descrito por Santurde et al. (1996) e em seguida foram incubadas a $56^{\circ} \mathrm{C}$ por 45 minutos em solução contendo $200 \mu \mathrm{L}$ de Chelex 100 a $5 \%, 2 \mu \mathrm{L}$ de proteinase $\mathrm{K}\left(10 \mathrm{mg} \mathrm{mL}^{-1}\right)$ e $7 \mu \mathrm{L}$ de dithiothreitol $1 \mathrm{M}$. Depois da centrifugação, por 10 segundos, a $13.000 \mathrm{~g}$, os tubos foram colocados em banho de água fervente por oito minutos e, a seguir, centrifugados por três minutos a $13.000 \mathrm{~g}$ (Walsh et al., 1991). O material foi acondicionado sob refrigeração até sua utilização na prova de PCR.

Na primeira etapa de amplificação, foram utilizados dois pares de oligonucleotídeos iniciadores, determinados a partir da região gag da amostra-padrão CAEV-Cork (Saltarelli et al., 1990), sendo os iniciadores P1 = 5'CAAGCAGCAGGAGGGAGAAGCTG-3' (posição genômica 953-975) e P2 = 5'TCCTACCCCC ATAATTTGATCCAC-3' (posição genômica 12491226) descritos por Barlough et al. (1994), que amplificaram um fragmento-alvo de $297 \mathrm{pb}$. Em seguida, foram utilizados os oligonucleotídeos iniciadores internos P3 = 5'GTTCCAGCAACTGCAA ACAGTAGCAA TG-3' (posição genômica 997-1024) e P4 = 5' ACCTT TCTGCTTCTTCATTTAATTTCCC 3' (posição genômica 1181-1154) para a segunda amplificação (Nested PCR), a fim de obter-se um fragmento-alvo final de $185 \mathrm{pb}$ (Rimstad et al., 1993).

A reação de PCR Nested foi realizada segundo método de Barlough et al. (1994), com algumas modificações. A reação consistiu de um volume total de $50 \mu \mathrm{L}$, contendo: tampão Tris $\mathrm{HCl}(\mathrm{pH} 8,3) 10 \mathrm{mM}$; $\mathrm{KCl} 50 \mathrm{mM}$; $\mathrm{MgCl}_{2}$ 1,5 mM; Gelatina 0,001\% (p/v); dNTP, $100 \mu \mathrm{M}$ de cada; TMAC $5 \mu \mathrm{M} ; 20$ pmol de cada oligonucleotídeo iniciador (ciclo 1 - iniciadores P1 e P2; ciclo 2 - iniciadores P3 e P4); Taq DNA polimerase (2 UI); $3 \mu \mathrm{L}$ amostra no ciclo 1 e $1 \mu \mathrm{L}$ de produto ciclo 1 no ciclo 2, sendo o volume final (qsp $50 \mu \mathrm{L}$ ) completado com água ultra pura autoclavada (Milli-Q - 18 ' $\Omega$; livre de DNAse).

As reações de amplificação foram realizadas em termociclador (Programmable Thermal Controller, PTC-100, MJ Research, Inc.), com os seguintes termais: um ciclo inicial para desnaturação a $94^{\circ} \mathrm{C}$, cinco minutos; seguido de 35 ciclos de $94^{\circ} \mathrm{C}$, um minuto; $56^{\circ} \mathrm{C}$, um minuto, $72^{\circ} \mathrm{C}$, 45 segundos; seguidos de extensão final a $72^{\circ} \mathrm{C}$, sete minutos e término a $4^{\circ} \mathrm{C}$. 
As amostras amplificadas e os controles positivo e negativo, além do marcador molecular, foram submetidos à eletroforese em gel de agarose 1\% em TBE (Tris, borato e EDTA 0,1X), corado com brometo de etídio $\left(0,5 \mu \mathrm{g} \mathrm{mL}^{-1}\right)$. Cada amostra $(15 \mu \mathrm{L})$, com $3 \mu \mathrm{L}$ de tampão da amostra, foi submetida a eletroforese em cuba horizontal, com TBE (0,5X), por 60 minutos (2 amp e 90 volts). A visualização dos fragmentos amplificados de DNA foi feita em transiluminador de luz ultravioleta, e fotodocumentada por câmera polaroide com filme preto-e-branco.

Para determinação da especificidade dos fragmentos amplificados, foi feita a análise de restrição por digestão com enzima Bal I. O protocolo foi realizado segundo as recomendações do fabricante. As amostras e os controles foram incubados a $37^{\circ} \mathrm{C}$, por uma noite e os produtos da restrição foram submetidos a eletroforese em gel de agarose conforme descrito. A enzima de restrição Bal I cliva a seqüência $5^{\prime}$...TGC $\downarrow$ CCA.....3' do fragmento alvo amplificado de $185 \mathrm{pb}$, resultando em dois fragmentos de 116 e 69 pb, respectivamente.

Na análise estatística dos resultados, utilizou-se o teste qui-quadrado e o teste de Tukey $(\mathrm{p}<0,05)$ através do programa EPI-INFO (Dean et al., 1992).

\section{Resultados e Discussão}

A utilização da PCR Nested permitiu a detecção de bandas de $185 \mathrm{pb}$ (Figura 1) que correspondem ao DNA pró-viral de LVC, em 20 amostras de sêmen

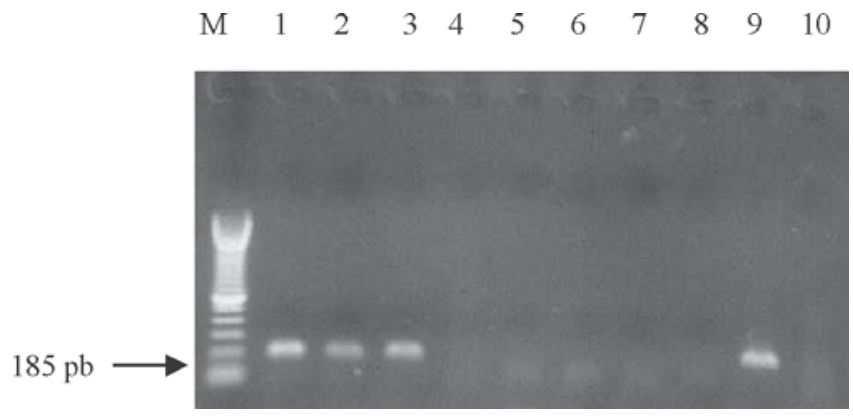

Figura 1. Gel de agarose 1\% corado com brometo de etídio. Reação em cadeia da polimerase - PCR Nested de amostras de sêmen de reprodutores caprinos infectados naturalmente com o lentivírus caprino, bandas de 185 pb. Canaleta $\mathrm{M}$ - marcador DNA Ladder; canaletas 1, 2 e 3 - amostras positivas; canaletas 4, 5, 6, 7 e 8-amostras negativas; canaleta 9-controle positivo; e canaleta 10 - controle negativo. criopreservados (35,7\%), a partir do total de 56 amostras analisadas. Esses resultados estão de acordo com Andrioli et al. (1999) e Travassos et al. (1999), que demonstraram a presença do LVC em sêmen de caprinos infectados.

Até recentemente, a detecção do LVC em amostras de sêmen não havia sido descrita, provavelmente em virtude da menor sensibilidade e dificuldades com as técnicas disponíveis até então para detecção das partículas virais no sêmen.

A detecção do DNA pró-viral do LVC no sêmen é fundamental para o programa de controle da AEC, considerando-se o risco de transmissão por meio de reprodutores infectados, quer sejam utilizados em monta natural quer em inseminação artificial (IA).

A lavagem do sêmen e o dano testicular foram fatores que influenciaram significativamente $(p<0,05)$ a presença do LVC no sêmen (Tabela 1). A lavagem do sêmen de caprino é um processo usual da Central de Tecnologia de Sêmen da Embrapa Caprinos, tendo em vista a presença de substâncias tóxicas aos espermatozóides, contidas no plasma seminal, no caso do sêmen ser criopreservado. A conjunção do dano testicular em animais infectados com a AEC demonstrou ser um fator que influencia a presença do LVC no sêmen, visto que $50 \%$ das amostras de sêmen coletadas depois do dano foram positivas, enquanto $21,4 \%$ das amostras coletadas antes do dano acusaram a presença do LVC $(\mathrm{p}<0,05)$ (Tabela 1$)$. O mesmo foi observado por Concha-Bermejillo et al. (1996), os quais isolaram o lentivírus ovino em sêmen de dois carneiros somente depois da infecção experimental com Brucella ovis.

A infecção local causada pelo dano testicular ficou evidente pelo exame de sangue, visto que houve pequeno

Tabela 1. Resultados da PCR Nested para a detecção do lentivírus caprino, em amostras de sêmen lavado ou não lavado, de reprodutores caprinos infectados naturalmente e submetidos a dano testicular.

\begin{tabular}{|c|c|c|c|c|}
\hline \multirow[t]{2}{*}{ Sêmen } & \multicolumn{2}{|c|}{ Pré-dano } & \multicolumn{2}{|c|}{ Pós-dano } \\
\hline & $\begin{array}{c}\text { Testadas } \\
\text { (n) }\end{array}$ & $\begin{array}{c}\text { Positivas } \\
(\%)\end{array}$ & $\begin{array}{c}\text { Testadas } \\
\text { (n) }\end{array}$ & $\begin{array}{c}\text { Positivas } \\
(\%)\end{array}$ \\
\hline Lavado & 14 & $7,1 \mathrm{a}$ & 14 & $28,6 \mathrm{a}$ \\
\hline Integral & 14 & $35,7 \mathrm{a}$ & 14 & $71,4 b$ \\
\hline Total & 28 & $21,4 \mathrm{~A}$ & 28 & $50,0 \mathrm{~B}$ \\
\hline
\end{tabular}

(1)Médias seguidas por letras minúsculas diferentes, na mesma coluna, e por letras maiúsculas diferentes, na mesma linha, diferem a $5 \%$ de probabilidade, pelo teste de Tukey. 
aumento do número de leucócitos, principalmente neutrófilos com tendência a um desvio à esquerda, retornando dez dias depois do dano, a valores próximos aos anteriores, o que indica um processo inflamatório, característico de infecção local.

Nas amostras totais de sêmen não lavado, 53,6\% foram positivos, enquanto no sêmen lavado, $17,9 \%$ das amostras apresentaram resultados positivos $(\mathrm{p}<0,05)$ (Tabela 1). Observa-se que a lavagem do sêmen pode reduzir a presença do vírus, porém não é suficiente para eliminá-los. A presença maior do LVC no sêmen integral demonstra o risco de transmissão do LVC pela monta natural.

Embora o risco de transmissão do LVC seja maior na monta natural, a inseminação artificial também apresenta potencial de disseminação da enfermidade, visto que o vírus está presente no sêmen lavado e criopreservado, o que requer grande atenção na comercialização e importação de sêmen.

Antes do dano testicular, 7,1\% das amostras lavadas foram positivas, indicando a presença do DNA pró-viral, mesmo em sêmen processado para criopreservação e inseminação artificial, oriundo de um animal que não tinha nenhuma outra enfermidade concomitante à AEC. Embora tenha sido demonstrado que o LVC está presente nas células não-espermáticas do sêmen, ou seja, nos leucócitos e não nos espermatozóides (Travassos et al., 1998, 1999), ressalta-se que a lavagem do sêmen não remove totalmente os leucócitos e sim o plasma seminal.

Quanto à sensibilidade do teste, a PCR Nested identificou as bandas esperadas entre $10^{4,5}$ a $10^{0,5} \mathrm{TCDI}_{50}$ por $50 \mu \mathrm{L}$ em sobrenadante de cultivo celular inoculado, quando se utilizaram os iniciadores externos. Com a realização da segunda etapa - PCR Nested, utilizando os iniciadores internos - as bandas esperadas foram obtidas entre $10^{4,5}$ e $10^{-4,5} \mathrm{TCDI}_{50}$ por $50 \mu \mathrm{L}$, indicando que a PCR Nested possui boa sensibilidade para identificação do DNA pró-viral do LVC, quando comparado com Rocha (1998), que obteve sensibilidade de $10^{5}$ a $10^{-3} \mathrm{TCDI}_{50}$ por $50 \mu \mathrm{L}$ para o HVB-1 por PCR Nested.

A especificidade das amplificações foi confirmada pela obtenção dos fragmentos esperados depois da restrição enzimática (enzima Bal I) dos produtos amplificados pelo PCR Nested das amostras de sêmen e do controle positivo.

O LVC foi detectado por isolamento viral, sendo observado a formação de sincícios na monocamada de
MSC (Figura 2). Esse resultado evidencia a viabilidade do LVC nas amostras de sêmen criopreservado, o que confirma que a congelação do sêmen possibilita sua sobrevivência assim como de outros microrganismos (Philpott, 1993).

A PCR demonstrou ser superior ao isolamento viral, já que, das 56 amostras submetidas ao isolamento, quatro foram positivas $(7,1 \%)$, enquanto a PCR detectou 20 amostras positivas (35,7\%), o que está de acordo com Smits et al. (2000), que encontraram maior positividade nas provas de PCR do que no isolamento viral do herpesvírus bovino em sêmen. Das quatro amostras positivas ao isolamento, três eram de amostras de sêmen não lavado, reforçando o fato de que o sêmen, na forma íntegra, tem maior probabilidade de conter o vírus.

A variação na detecção do LVC, em ejaculados do mesmo animal, sugere que a presença do DNA próviral no sêmen de caprino não é constante, ou pode estar em quantidades mínimas não detectáveis. Esse fato está de acordo com Jordan et al. (1999), que observaram que a presença do lentivírus no ejaculado de gatos varia tanto entre animais quanto nos vários ejaculados do mesmo animal, e com Concha-Bermejillo et al. (1996), que observaram que a presença do MVV em sêmen de ovinos é intermitente.

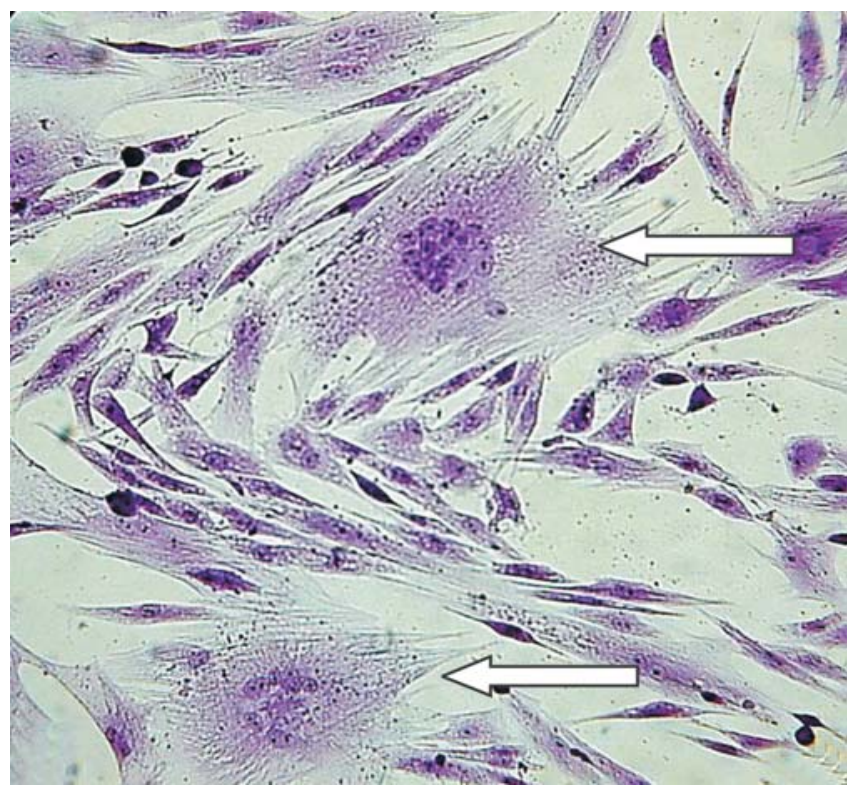

Figura 2. Sincício (setas) em cultura primária de MSC inoculada com sêmen de reprodutores caprinos infectados naturalmente com o lentivírus caprino, coloração cristal violeta $0,1 \%$, aumento 200X. 


\section{Conclusões}

1. A lavagem do sêmen caprino diminui a carga viral, porém não elimina, totalmente, o lentivírus caprino no sêmen.

2. O dano testicular é um fator que influencia a presença do lentivírus caprino no sêmen.

\section{Agradecimentos}

Ao CNPq e à Fapemig, pelo auxílio financeiro.

\section{Referências}

ADAMS, D.S.; KLEVJER-ANDERSON, P.; CARLSON, J.L.; McGUIRE, T.C.; GORHAM, J.R. Transmission and control of caprine arthritis-encephalitis virus. American Journal of Veterinary Research, v.44, p.1670-1675, 1983.

ALEXANDER, N.J. Sexual transmission of human immunodeficiency virus: virus entry into the male and female genital tract. Fertility and Sterility, v.54, p.1-18, 1990.

ANDRIOLI, A.; GOUVEIA, A.M.G.; PINHEIRO, R.R.; ROCHA, M.A.; MARTINS, A.S.; SANTOS, D.O. Deteç̧ão do DNA próviral do lentivírus caprino em sêmen de bodes naturalmente infectados. Revista Brasileira de Reprodução Animal, v.23, p.420-421, 1999.

BARLOUGH, J.; EAST, N.; ROWE, J.D.; HOOSEAR, K.V.; DEROCK, E.; BIGORNIA, L.; RIMSTAD, E. Double-nested polymerase chain reaction for detection of caprine arthritisencephalitis virus proviral DNA in blood, milk, and tissues of infected goats. Journal of Virological Methods, v.50, p.101-113, 1994.

BIELANSKI, A.; DUBUC, C.; HARE, W.C.D. Failure to remove bovine diarrhea virus (BVDV) from bull semen by swim-up and other separatory sperm techniques associated with in vitro fertilization. Reproduction in Domestic Animals, v.27, p.303306, 1992.

CONCHA-BERMEJILLO, A. de la; MAGNUS-CORRAL, S.; BRODIE, S.J.; DeMARTINI, J.C. Venereal shedding of ovine lentivirus in infected rams. American Journal of Veterinary Research, v.57, p.684-688, 1996.

DEAN, A.G.; DEAN, J.A.; BURTON, A.H.; DICKER, R.C. Epi info, version 6: a word processing, database and statistic program for epidemiology on micro-computers. Atlanta, Georgia: Center for Disease Control, 1992. 302p.

HARE, W.C.D. Enfermedades transmissibles por el semen y las tecnicas de transferencia de embriones. France: Office International des Epizooties, 1985. 83p. (Serie técnica, 4).

HIGUCHI, R. Rapid, efficient DNA extraction for PCR from cells or blood. Amplifications, v.1, p.1-3, 1989.

JORDAN, H.L.; HOWARD, J.; TOMPKINS, W.A.; KENNEDYSTOSKOPF, S. Detection of feline immunodeficiency virus in semen from seropositive domestic cats (Felis catus). Journal of Virology, v.69, p.7328-7333, 1995.
JORDAN, H.L.; LIANG, Y.H.; HUDSON, L.C.; TOMPKINS, W.A. Shedding of feline immunodeficiency virus in semen of domestic cats during acute infection. American Journal of Veterinary Research, v.60, p.211-215, 1999.

MERMIN, J.H.; HOLODNIY, M.; KATZENSTEIN, D.A.; MERIGAN, T.C. Detection of human immunodeficiency virus DNA and RNA in semen by the polymerase chain reaction. Journal of Infectious Diseases, v.164, p.769-772, 1991.

NASH, J.W.; HANSON, L.A.; COATS, K.C. Bovine immunodeficiency virus in stud bull semen. American Journal of Veterinary Research, v.56, p.760-763, 1995.

PHILPOTT, M. The dangers of disease transmission by artificial insemination and embryo transfer. British Veterinary Journal, v.149, p.339-369, 1993.

PREZIUSO, S.; SANNA, E.; SANNA, M.P.; LODDO, C.; CERRI, D.; TACCINI, E.; MARIOTTI, F.; BRAGA, G.; ROSSI, G.; RENZONI, G. Association of Maedi visna virus with Brucella ovis infection in rams. European Journal of Histochemistry, v.47, p.151-157, 2003.

QUAYLE, A.J.; XU, C.; MAYER, K.H.; ANDERSON, D.J. T lymphocytes and macrophages, but not motile spermatozoa, are a significant source of human immunodeficiency virus in semen. Journal of Infectious Diseases, v.176, p.960-968, 1997.

RIMSTAD, E.; EAST, N.E.; TORTEN, M.; HIGGINS, J.; DEROCK, E.; PEDERSEN, N.C. Delayed seroconversion following naturally acquired caprine arthritis-encephalitis virus infection in goats. American Journal of Veterinary Research, v.54, p.18581862, 1993.

ROCHA, M.A. Desenvolvimento de um sistema de PCR Nested para a detecção do herpesvírus bovino-1 em sêmen e feto abortado. 1998. 94p. Tese (Doutorado) - Universidade Federal de Minas Gerais, Belo Horizonte.

ROWE, J.D.; EAST, N.E.; THURMOND, M.C.; FRANTI, C.E.; PEDERSEN, N.C. Cohort study of natural transmission and two methods for control of caprine arthritis-encephalitis virus infection in goats on a California dairy. American Journal of Veterinary Research, v.53, p.2386-2395, 1992.

SALTARELLI, M.; QUERAT, G.; KONINGS, D.A.M.; VIGNE, R.; CLEMENTS, J.E. Nucleotide sequence and transcriptional analysis of molecular clones of CAEV which generate infectious virus. Virology, v.179, p.347-364, 1990.

SANTURDE, G.; SILVA, N. da; VILLARES, R.; TABARES, E.; SOLANA, A.; BAUTISTA, J.M.; CASTRO, J.M. Rapid and high sensitivity test for direct detection of bovine herpesvirus-1 genome in clinical samples. Veterinary Microbiology, v.49, p.81-92, 1996.

SMITS, C.B.; VAN MAANEM, C.; GLAS, R.D.; DE GEE, A.L.; DIJKSTRAB, T.; VAN OIRSCHOT, J.T.; RIJSEWIJK, F.A. Comparison of three polymerase chain reaction methods for routine detection of bovine herpesvirus 1 DNA in fresh bull semen. Journal of Virological Methods, v.85, p.65-73, 2000.

THIBIER, M.; GUÉRIN, B. Hygienic aspects of storage and use of semen for artificial insemination. Animal Reproduction Science, v.62, p.233-251, 2000. 
TRAVASSOS, C.E.; BENOÎT, C.; VALAS, S.; SILVA, A.G. da; PERRIN, G. Caprine arthritis-encephalitis virus in semen of naturally infected bucks. Small Ruminant Research, v.32, p.101-106, 1999. TRAVASSOS, C.E.; BENOÎT, C.; VALAS, S.; SILVA, A.G. da; PERRIN, G. Détection du virus de l'arthrite encéphalite caprine dans le sperme de boucs infectés expérimentalement. Veterinary Research, v.29, p.579-584, 1998.

WALSH, P.S.; METZGER, D.A.; HIGUCHI, R. Chelex 100 as a medium for simple extraction of DNA for PCR-based typing from forensic material. Biotechniques, v.10, p.506-513, 1991.

Recebido em 18 de julho de 2005 e aprovado em 8 de maio de 2006 